\title{
Cabell's Directory of Publishing Opportunities in Educational Psychology and Administration
}

Edited by David W. E. Cabell and Deborah L. English

Cabell Publishing Company, Beaumont, TX, 2002, 799 pp.

ISBN \#0-911753-19-2

\section{Reviewed by Myron L. Pope \\ Assistant Professor, Adult and Higher Education \\ University of Oklahoma}

The internet is not exhaustive. Library stacks can be imcomplete. Personal knowledge can go only so far. And Cabell's Director not only fills in those blanks, it expand opportunity. Cabell's Directory of Publishing Opportunities in Educational Psychology and Administration (Directory) is one of the most valuable and perhaps underutilized resources in the entire higher education industry.

For many researchers and practitioners who are interested in publishing a manuscript, the process can be perplexing, so the Directory provides the guidelines for publication for over 225 journals classified under twenty-eight topic areas. These topical areas include adult career and vocational, counseling and psychological services, education management/administration, higher education, and urban education, among others. The Directory also provides information about the review process, number of external reviewers, and acceptance rate for these journals.

As there are various writing styles required for varying journals, including the Chicago Manual of Style and the Publication Manual of the American Psychological Association, the Directory provides specific guidelines about the style and format requirements of most of the included journals. This specifically applies to those journals that have their own unique publication submission guidelines.

Also important in considering the compatibility of a manuscript for publication in one of these educational journals is an understanding of the review process. The Directory provides instructions on the type of review process utilized by the editor(s), the number of reviewers, the acceptance rates, the amount of time required for review, the availability of the reviewers' comments, any fees required for review and publication of the manuscript, the number of copies of the manuscript required for review, and also potential manuscript topics. These characteristics of the Directory allow an author to narrow down the number of journals that will be interested in publishing a work. The Directory assists an author in determining which journal is most appropriate for a topic, format, or design, and can save an author time and resources by educating an author about a journal's expectations.

The Directory also does an excellent job of defining what a "refereed article" is, and additionally assists in understanding the steps that are included in the process of publishing a refereed article. For example, the Directory provides information about relating the theme of a manuscript to the topics published by each journal, sending the manuscript, and understanding the comments of the reviewers regarding a manuscript. These guidelines are important in not only ensuring that the proper journal is selected 
and submitted, but it also allows for an understanding of what to expect and how to respond to reviewer comments.

The Sixth Edition (2002-03) Directory for educational psychology and administration, which is edited by David W. E. Cabell of McNeese State University, is divided into two separate volumes. These volumes are divided alphabetically: A-J and $\mathrm{J}-\mathrm{Z}$. There is also a separate directory which specifically focuses on educational curriculum and methods for those individual researchers who need publication guidance in these areas of specialization. The educational psychology and administration volumes can be published for $\$ 89.95$ through www.cabells.com, or by contacting the company at Cabell's Publishing Company in Texas. The educational curriculum and methods volume, which contains 350 journals categorized under twenty-eight topics, can be purchased for $\$ 99.95$ through the same outlets.

The Directory is an exceptional resource for faculty members and graduate students, but it is also an excellent resource for virtually any student affairs office. Every vice president's office should have one copy. This type of resource can expand opportunities for the orientation professional, and provide excellent direction for research or best practice queries. 